\title{
The Depreciation of the Pound Post-Brexit: Could it have been Predicted?
}

\author{
Vasilios Plakandaras $^{*+}$, Rangan Gupta ${ }^{* *}$ and Mark E. Wohar ${ }^{* * *}$ \\ ${ }^{+}$Department of Economics, Democritus University of Thrace, Greece; Email: \\ vplakand@econ.duth.gr. \\ *Department of Economics, University of Pretoria, South Africa; Email: \\ rangan.gupta@up.ac.za. \\ *** College of Business Administration, University of Nebraska at Omaha \\ USA, and School of Business and Economics, Loughborough University, UK; Email: \\ mwohar@unomaha.edu.
}

\begin{abstract}
The decision of the United Kingdom to leave the European Union (Brexit) after 43 years caused turmoil in exchange rate and global stock markets. More specifically, the pound relative to the dollar has lost close to 15 percent of its value in the weeks after the Brexit decision. In this paper we attempt to examine whether this sudden depreciation of the (pound-dollar) exchange rate is the reaction of market participants to the Brexit or whether the exodus of UK from the EU had little impact on the exchange rate. In doing so, we train linear and nonlinear econometric and machine learning models and evaluate out-of-sample forecasts of the exchange rate and its realized volatility in the pre- and post-Brexit period. We quantify uncertainty caused by the Brexit according to an index based on news related to economic uncertainty. We argue that in daily forecasting horizon our models adhere closely to the evolution of the exchange rate and that most of the depreciation is based on the uncertainty caused by the Brexit.
\end{abstract}

Keywords: Brexit, Economic Uncertainty, Machine Learning

JEL Codes: F31, F37

\footnotetext{
${ }^{*}$ To whom correspondence should be addressed.
} 


\section{Introduction}

On the $13^{\text {th }}$ of January 2013 the former Prime Minister of UK David Cameron announced a referendum on whether the United Kingdom (UK) should remain or leave the European Union (EU). This decision instigated a series of events that finally lead to the decision on the $23^{\text {rd }}$ of June 2016 to leave the EU. This significant political and historical event caused financial markets to decline, leading the British pound sterling to drop sharply. More specifically, on the $27^{\text {th }}$ of June 2016 the pound fell to $£ 1.315$ to the US dollar, reaching its 31 -year low since 1985 , below the value of sterling's "Black Wednesday" of $1992^{1}$. This rapid devaluation resulted in the pound losing almost $10 \%$ of its value in just one trading day. A natural question that arises from this sudden turmoil in the exchange rate is whether the actual magnitude of the depreciation could have been foreseen.

The series of events that finally led to the UK leaving the EU span both the political and economic life of the UK, making it hard to explicitly isolate the effects on the exchange rate. Towards this end, we quantify the uncertainty of the Brexit based on the uncertainty indices developed by Baker et al. (2015). As stated by the authors, uncertainty seems to co-evolve with economic and financial turmoil. The authors produce various indices according to the ratio of articles in newspapers that discuss economics and use "uncertain" or "uncertainty", "economic" or "economy", and one or more policy-relevant terms (“tax", "policy”, "regulation”, "spending”, “deficit”, "budget", or "central bank").

For the US and the UK the authors produce daily Economic Policy Uncertainty (EPU) indices updated monthly. Moreover, on the aftermath of the announcement of the referendum they produced a monthly Brexit dedicated sub-index. This dedicated subindex compiles data from the Financial Times and the Times of London. The subindex includes only the ratio of the articles that use the term "Brexit", "EU" and "European Union", besides the terms (economy, uncertainty and policy) used for the construction of the UK EPU index.

\footnotetext{
${ }^{1}$ On that date the pound was forced out of the European Exchange Rate Mechanism, since it did not comply with the lower boundary of the ERM.
} 
For our purpose, we use both linear and nonlinear models with and without the Brexit related indices to forecast the pound-dollar exchange rate logarithmic returns. Specifically, we choose the most accurate models in forecasting the pound-dollar exchange rate based on a pseudo out-of-sample forecasting exercise until May, 2016, and then forecast ex ante the exchange rate for June, 2016 to compare with the actual data. The decision to use a nonlinear approach emanates from the wide-spread evidence of nonlinearity in the behavior of the exchange rate on its own and in its relationship with its predictors (Balcilar et al., 2016). We employ a machine learning framework (Support Vector Regressions) in our paper to capture nonlinearity, motivated by the recent evidence of superior exchange rate forecasts produced by this type of model, as provided by Plakandaras et al., (2015).

A few drawbacks of the Brexit index are its monthly frequency and the fact that it ends in May 2016. In a monthly frequency the potential fluctuations in the evolution of the exchange rate are smoothed out. On the other hand, most of the depreciation in the exchange rate occurred in the post-Brexit period, a period not included in the index. In order to account for these drawbacks, we reconsider our forecasting exercise exploiting the daily UK EPU.

The rest of the paper is organized as follows: Section 2 presents the data and the methodology, while Section 3 presents the out-of-sample forecasting results. Section 4 concludes the paper with a discussion of the results.

\section{Data and Methodology}

\section{$2.1 \quad$ The Data}

We compile daily and monthly (average of the daily) observations of the USD/GBP exchange rate for the period 2000M01-2016M05 over which the Brexit related EPU index is available. Daily data are compiled for the period 01/01/2001 - 08/08/2016 The exchange rate data are available from the FRED database of the Federal Reserve Bank of St. Louis, while the Brexit related EPU is available from: http://www.policyuncertainty.com/brexit.html. As is obvious from Figure 1, the UK EPU and the Brexit EPU indices co-evolve in time, with the Brexit EPU sub-index capturing a significant part of the overall economic uncertainty in the $\mathrm{UK}$ in the post 2013 period. More specifically, while the overall correlation coefficient of the two 
EPU indices is 0.65 , in the period 2000-2013 the correlation is 0.58 , while after the announcement of the referendum in January 2013 the correlation rises to 0.90 .

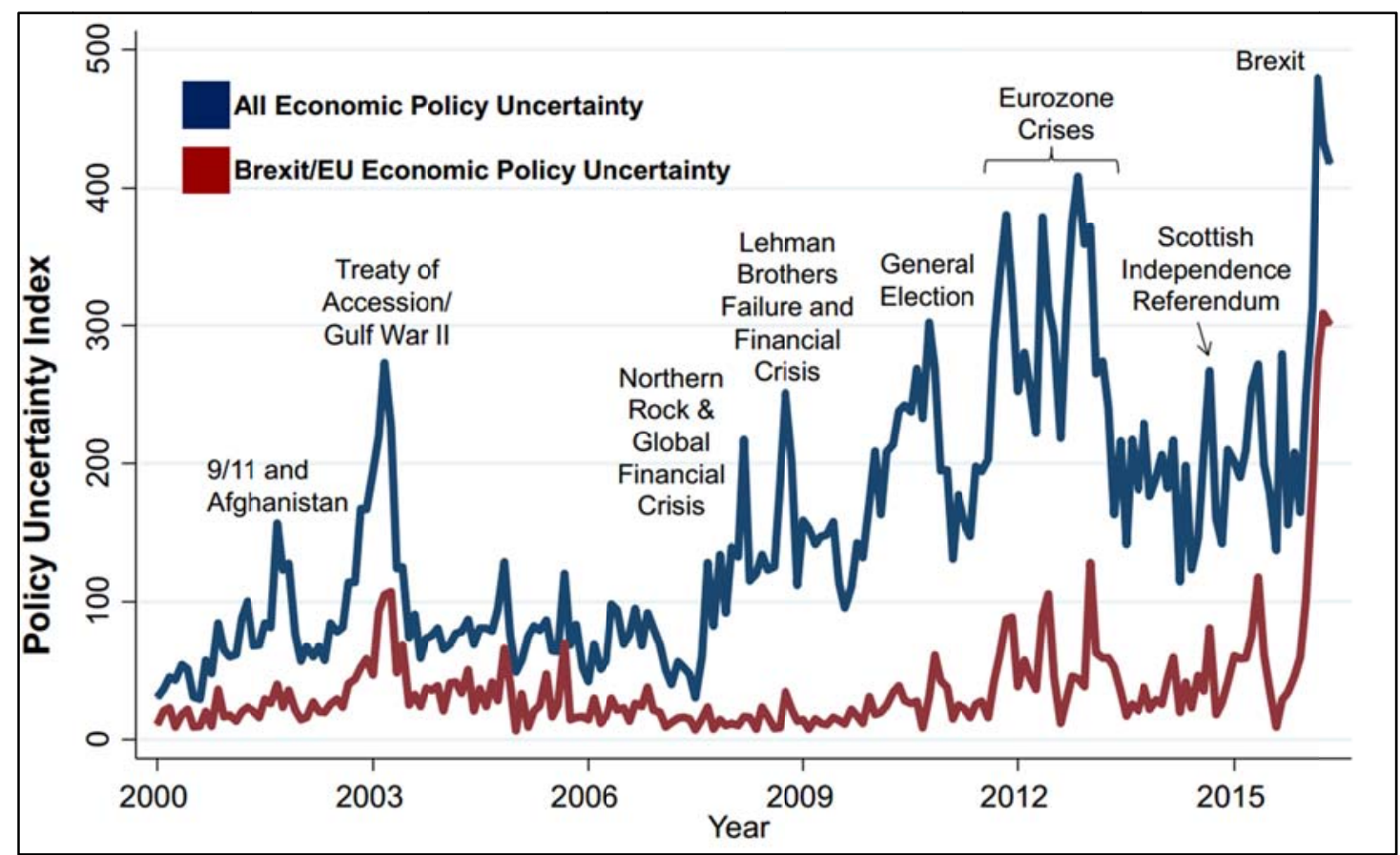

Figure 1: United Kingdom Economic Policy Uncertainty: All and Brexit/EU. (Source: http://www.policyuncertainty.com/images/Brexit_Figure.pdf.)

Note: The "All EPU" Index reflects scaled monthly counts of articles containing 'uncertain' or 'uncertainty', 'economic' or 'economy', and one or more policy-relevant terms ('tax', 'policy', 'regulation', 'spending', 'deficit', 'budget', or 'central bank'). The series is normalized to mean 100 from 1997 to 2011 and based on queries from The Times of London and the Financial Times. We obtain the other index by multiplying the "All EPU" index by the share of EPU articles that contain 'Brexit', 'EU' or 'European Union'.

Since the exchange rate is the relative relationship between the two currencies, we take the logarithmic differences between the US and the Brexit EPU indices in order to obtain a relative measure between the uncertainty of the two economies. The US EPU data is obtained from: http://www.policyuncertainty.com/us monthly.html. In Table 1, we report the descriptive statistics and unit root tests for all series on monthly and daily frequency, respectively.

\begin{tabular}{|c|c|c|c|c|c|c|c|c|c|}
\hline & \multirow{3}{*}{ Mean } & \multirow{3}{*}{$\begin{array}{c}\text { Standard } \\
\text { Deviation }\end{array}$} & \multirow{3}{*}{ Skewness } & \multirow{3}{*}{ Kurtosis } & \multirow{3}{*}{$\begin{array}{l}\text { Jarque-- } \\
\text { Bera test }\end{array}$} & \multirow{2}{*}{\multicolumn{2}{|c|}{$\begin{array}{l}\text { Augmented Dickey- } \\
\text { Fuller test }\end{array}$}} & \multirow{2}{*}{\multicolumn{2}{|c|}{ Phillips-Perron test }} \\
\hline & & & & & & & & & \\
\hline & & & & & & Constant & $\begin{array}{c}\text { Constant } \\
\text { anid } \\
\text { trend }\end{array}$ & Constant & $\begin{array}{l}\text { Constant } \\
\text { and trend }\end{array}$ \\
\hline USD/GBP & 1.65 & 0.17 & 0.71 & 2.46 & $19.15^{* *}$ & -1.85 & -1.89 & -1.81 & -1.85 \\
\hline $\begin{array}{l}\text { Exchange rate } \\
\text { returns }\end{array}$ & $-10.45 \mathrm{e}-04$ & $4.84 \mathrm{e}-04$ & -0.58 & 5.04 & $33.96 * *$ & $-10.20 * *$ & $-10.20 * *$ & $-10.33 * *$ & $-10.32 * *$ \\
\hline $\begin{array}{c}\text { Realized } \\
\text { Volatility }\end{array}$ & $7.23 e-04$ & $8.59 \mathrm{e}-04$ & 5.07 & 33.41 & $8390 * *$ & $-4.52 * *$ & $-4.51 * *$ & $-5.91 * *$ & $-5.89 * *$ \\
\hline Brexit EPU & 37.03 & 40.93 & 4.34 & 26.33 & $15.58^{* *}$ & $-3.71 * *$ & $-4.24 * *$ & $-6.58 * *$ & $-7.29 * *$ \\
\hline
\end{tabular}




\begin{tabular}{|c|c|c|c|c|c|c|c|c|c|}
\hline $\begin{array}{c}\text { Relative Brexit } \\
\text { EPU } \\
\end{array}$ & -1.38 & 0.73 & 0.49 & 4.29 & $21.40 * *$ & $-3.45^{*}$ & $-3.68 *$ & $-5.98 * *$ & $-6.41 * *$ \\
\hline
\end{tabular}

Note: $* *$ and $*$ denote rejection of the null hypothesis at $1 \%$ and $5 \%$ levels of significance.

\begin{tabular}{|c|c|c|c|c|c|c|c|c|c|}
\hline & & able 2: & \multirow{3}{*}{ Skewness } & \multirow{3}{*}{ Kurtosis } & \multirow{3}{*}{$\begin{array}{l}\text { Jarque-- } \\
\text { Bera test }\end{array}$} & of daily da & & & \\
\hline & \multirow{2}{*}{ Mean } & \multirow{2}{*}{$\begin{array}{c}\text { Standard } \\
\text { Deviation }\end{array}$} & & & & \multicolumn{2}{|c|}{$\begin{array}{l}\text { Augmented Dickey- } \\
\text { Fuller test }\end{array}$} & \multicolumn{2}{|c|}{ Phillips-Perron test } \\
\hline & & & & & & Constant & $\begin{array}{c}\text { Constant } \\
\text { and } \\
\text { trend }\end{array}$ & Constant & $\begin{array}{l}\text { Constant } \\
\text { and trend }\end{array}$ \\
\hline \multicolumn{10}{|l|}{ Exchange rate } \\
\hline UK EPU & 5.43 & 0.77 & -2.12 & 14.53 & $24658 * *$ & $-5.44 * *$ & $-5.75 * *$ & $-71.19 * *$ & $-72.61 * *$ \\
\hline Relative EPU & -1.01 & 0.79 & 1.25 & 10.34 & $9820 * *$ & $-11.06 * *$ & $-11.75 * *$ & $-73.26 * *$ & $-71.57 * *$ \\
\hline
\end{tabular}

Note: $* *$ denote rejection of the null hypothesis at $1 \%$ level of significance.

As we observe from Tables 1 and 2, we reject the null hypothesis of normality for all series. According to the Augmented Dickey - Fuller (Dickey and Fuller, 1981) and the Phillips - Perron (Phillips and Perron, 1988) tests, the null hypothesis about the existence of a unit root cannot be rejected at 5\% level of significance for the monthly exchange rate. In contrast the Brexit EPU and the relative Brexit EPU are stationary. Thus, in the rest of the paper, we use first logarithmic differences for both for the monthly and the daily exchange rate (i.e., exchange rate returns), while we take loglevels of the Brexit EPU, and levels of the relative Brexit EPU index. Daily UK EPU and the relative EPU are also used in levels. Note stationarity is required by our linear and nonlinear estimation approaches. We also measure the realized volatility of the monthly exchange rate as a measure of volatility, and thus a measure of the risk in trading the exchange rate. For this purpose, we use the sum of the daily squared returns over the specific month under consideration (Andersen and Bollerslev, 1998).

\subsection{Methodology}

In general, exchange rates exhibit high volatility and often the data generating process is nonlinear (Macdonald, 2010; Balcilar et al., 2016). Thus, in our study apart from linear Ordinary Least Square models we also examine the nonlinear Support Vector Regression (SVR) methodology (Vapnik et al., 1992). The high forecasting ability of the methodology has attracted significant interest in forecasting economics and financial time series (Rubio et al., 2011; Plakandaras et al., 2015).

The basic idea is to find a linear function that has at most a predetermined deviation from the actual values of the dataset. In other words, we do not care about the error of each forecast as long as it doesn't violate the predefined threshold, but we penalize 
any deviations higher than the threshold. The set that bounds this "error-tolerance band" is the Support Vector (SV). This, is located through a minimization procedure.

Using mathematical notation and starting from a training dataset $D=\left[\left(\boldsymbol{x}_{1}, y_{1}\right),\left(\boldsymbol{x}_{2}, y_{2}\right), \ldots .\left(\boldsymbol{x}_{n}, y_{n}\right)\right], \boldsymbol{x}_{i} \in \mathbb{R}^{m}, y_{i} \in \mathbb{R}, i=1,2, \ldots . n$, where for each observation pair, $\boldsymbol{x}_{i}$ are the observation samples and $y_{i}$ is the dependent variable (the target of the regression system) the linear regression function takes the form of $f(\boldsymbol{x})=\boldsymbol{w}^{T} \boldsymbol{x}+b$. The SVR methodology tries to reach two contradictory goals: a) find a solution that best approximates the given dataset (i.e. a large part of the data points should be inside the tolerance "belt", while a few points will lie out of bounds) and $b$ ) to find a solution that generalizes to the underlying population. This is achieved by solving:

$$
\begin{gathered}
\min \left(\frac{1}{2}\|\boldsymbol{w}\|^{2}+C \sum_{i=1}^{n}\left(\zeta_{i}+\zeta_{i}^{*}\right)\right) \\
\text { subject to }\left\{\begin{array}{c}
y_{i}-\left(\boldsymbol{w} \boldsymbol{x}_{i}+b\right) \leq \varepsilon+\zeta_{i} \\
\left(\boldsymbol{w} \boldsymbol{x}_{i}+b\right)-y_{i} \leq \varepsilon+\zeta_{i}^{*} \\
\zeta_{i}, \zeta_{i}^{*} \geq 0
\end{array}\right.
\end{gathered}
$$

where $\varepsilon$ defines the tolerance belt around the regression, and $\zeta_{i}, \zeta_{i}^{*}$ are slack variables controlled through a penalty parameter $\mathrm{C}$ (see Figure 2). All the points inside the tolerance belt have $\zeta_{i}, \zeta_{i}^{*}=0$. 


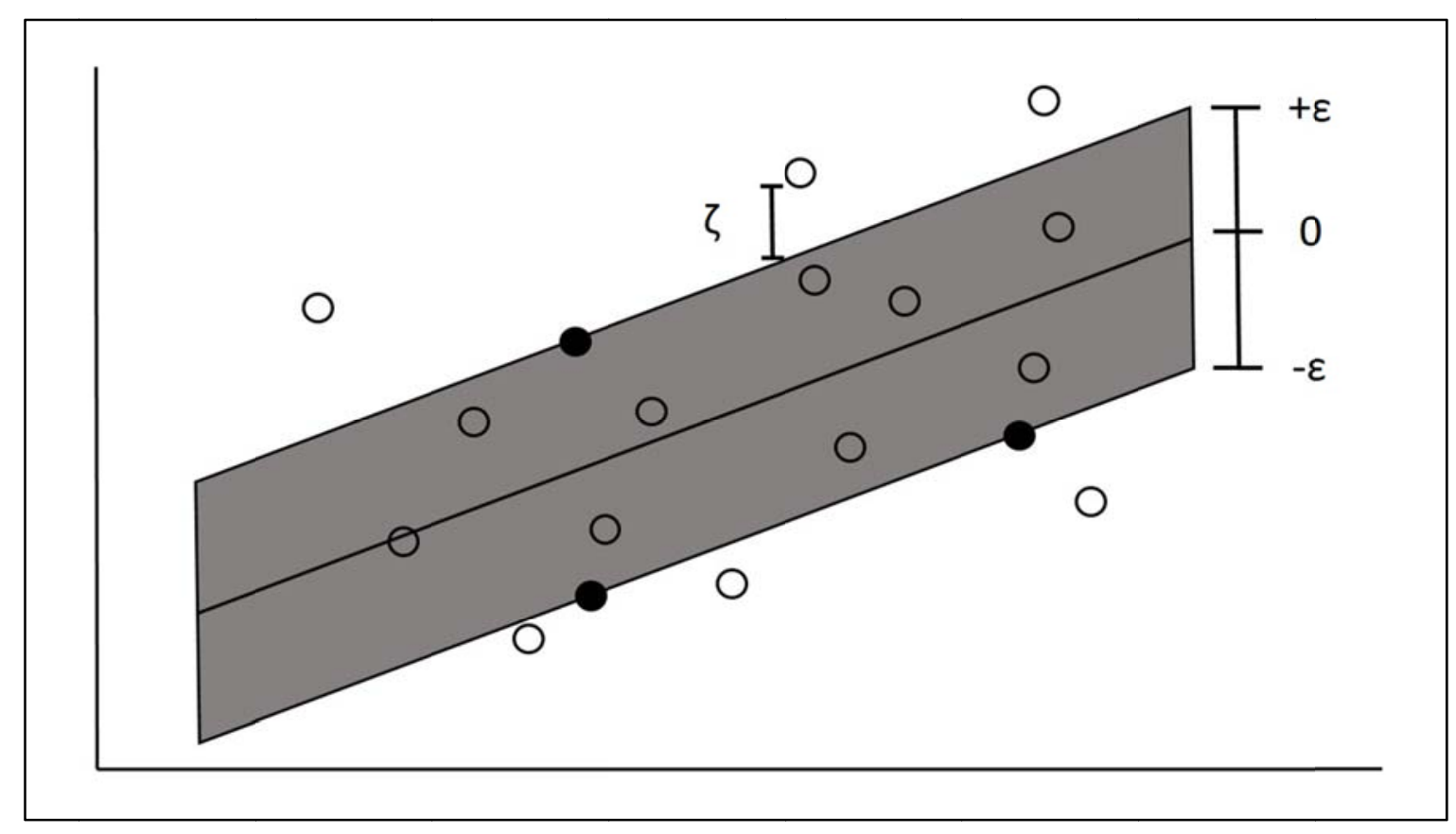

Figure 2: Upper and lower threshold on error tolerance indicated with letter $\varepsilon$.

Note: The boundaries of the error tolerance band are defined by the Support Vectors (SVs) denoted with the black filled points. Forecasted values greater than $\varepsilon$ get a penalty $\zeta$ according to their distance from the tolerance accepted band.

Real life phenomena are rarely described correctly by a linear regression; they are too complex for such a simplistic approximation. The "kernel trick" follows the projection idea while ensuring minimum computational cost: the dataset is mapped in an inner product space, where the projection is performed using only dot products within the original space through special "kernel" functions, instead of explicitly computing the mapping of each data point. Non-linear kernel functions have evolved the SVR mechanism to a non-linear regression model. In our simulations we employed four kernels: the linear, the radial basis function (RBF), the sigmoid and the polynomial $^{2}$.

\section{Empirical Results}

\subsection{Monthly results}

A visual inspection of the USD/GBP exchange rate provides that in the post 2008 period the exchange rate depreciates significantly, while the realized volatility exhibits a spike at the aftermath of the 2008 global financial crisis (Figure 3).

\footnotetext{
${ }^{2}$ Our implementation of SVR models is based on the LIBSVM algorithm (Chang and Lin, 2011).

Software is available at: http://www.csie.ntu.edu.tw/ cjlin/libsvm/.
} 

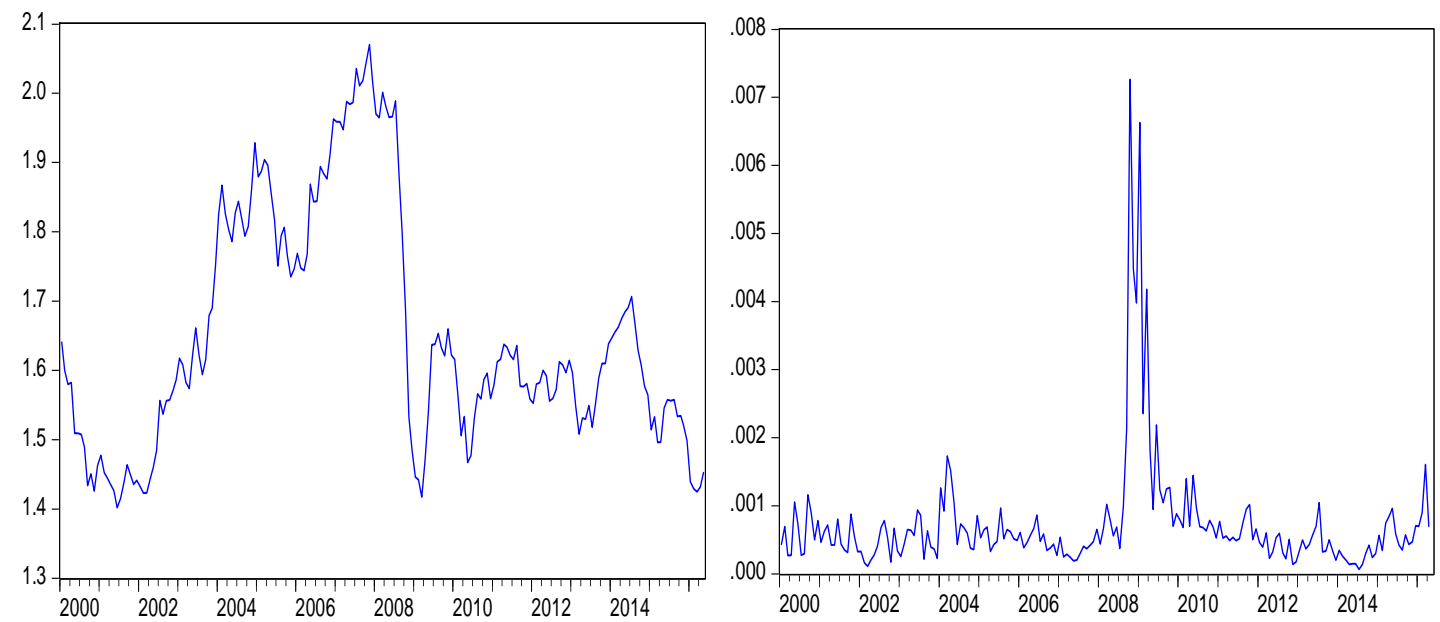

Figure 3: USD/GBP monthly exchange rate and realized volatility.

In order to select the most accurate model we use the period 2000:02-2007:12 as the training sample and keep the period 2008:01-2016:05 for out-of-sample forecasting, with the out-of-sample being in line with the global financial crisis and the extreme behavior depicted in Figure 3. Then we forecast ex-ante the exchange rate value for June 2016. Among the variety of forecasting models, we select the one with the smallest Root Mean Square Error in the unknown data (out-of-sample forecasts). In this way we are able to select the model that adheres more closely to the exchange rate before the Brexit and then extrapolate in the post-Brexit period. The model under examination is given by:

$$
U S D / G B P_{t}=\beta_{0}+\beta_{1} U S D / G B P_{t-k}+\beta_{2} X_{t-k}+u_{t}
$$

where $k=1,2, \ldots, 13$ is the lag order (selected according to the minimum RMSE), $X$ a matrix of regressors and $u$ normally distributed errors. Starting from an Autoregressive $(\mathrm{AR})$ model $\left(\beta_{2}=0\right)$, we extend to structural models of the uncertainty and relative uncertainty indices $\left(\beta_{1}=0\right)$ coded Brexit and relative Brexit and finally structural models that combine AR and uncertainty indices (the full equation 2). In Tables 3 and 4 we report the RMSE for the exchange rate and the realized variance, accordingly.

\begin{tabular}{l|c|c|c|c|c}
\hline \hline \multicolumn{1}{c}{ Table 3: Root Mean Square Error for Out-of-Sample Forecasting of Exchange Rate Returns } \\
\hline Regressors & $\begin{array}{c}\text { OLS } \\
\text { RMSE } \times 10)\end{array}$ & $\begin{array}{c}\text { SVR-linear } \\
\text { RMSE } \times \\
10)\end{array}$ & $\begin{array}{c}\text { SVR-RBF } \\
(\text { RMSE } \times \\
10)\end{array}$ & $\begin{array}{c}\text { SVR-Sigmoid } \\
\text { (RMSE } \times 10)\end{array}$ & $\begin{array}{c}\text { SVR-Poly } \\
\text { RMSE } \times \\
10)\end{array}$ \\
\hline AR & 0.364 & 0.365 & 0.365 & 0.416 & $0.361^{*}$ \\
Brexit & 0.386 & 0.377 & 0.379 & 0.377 & 0.376 \\
Relative Brexit & 0.383 & 0.383 & 0.369 & 1.498 & NC \\
\hline \hline
\end{tabular}




\begin{tabular}{l|l|l|l|l|l}
\hline \hline AR-Brexit & 0.366 & 0.368 & 0.384 & 0.363 & NC \\
AR- Relative Brexit & 0.368 & 0.365 & 0.381 & 0.566 & NC \\
\hline \hline
\end{tabular}

Note: * denotes the smallest RMSE in out-of-sample forecasting. NC denotes that the model did not converge.

\begin{tabular}{lccccc}
\hline \hline \multicolumn{5}{c}{ Table 4: Root Mean Square Error for Out-of-Sample Forecasting of the Realized Volatility } \\
\hline Regressors & OLS & $\begin{array}{c}\text { SVR-linear } \\
\text { (RMSE } \times\end{array}$ & $\begin{array}{c}\text { SVR-RBF } \\
\text { (RMSE } \times\end{array}$ & $\begin{array}{c}\text { SVR-Sigmoid } \\
\text { (RMSE } \times\end{array}$ & $\begin{array}{c}\text { SVR-Poly } \\
\text { (RMSE } \times\end{array}$ \\
\hline AR & 0.615 & 0.089 & 0.109 & 0.112 & $100)$ \\
Brexit & 0.589 & 0.123 & 0.121 & 0.121 & 0.119 \\
Relative Brexit & 0.611 & 0.124 & 0.117 & 0.123 & 0.110 \\
AR-Brexit & 0.609 & 0.085 & 0.112 & $0.074^{*}$ & 0.090 \\
AR- Relative Brexit & 0.605 & 0.087 & 0.116 & 0.111 & 0.093 \\
\hline \hline
\end{tabular}

Note: * denotes the smallest RMSE in out-of-sample forecasting.

As we observe from Table 3, the model that adheres closely to the evolution of the exchange rate is the SVR Autoregressive (AR) model based on the Polynomial kernel. Nevertheless, the difference in the RMSE between the nonlinear and the linear model is statistically insignificant ${ }^{3}$. In contrast, the SVR (Sigmoid) structural model of the Brexit EPU and lags of the dependent variable is the most accurate one in forecasting the realized volatility (Table 4). Especially in the realized volatility case, the nonlinear method exhibits almost 100 times smaller RMSE in out-of-sample forecasting than the linear OLS model. Thus, the selection of the nonlinear approach and the additional computational effort in training nonlinear machine learning models is justified only for the realized variance.

As stated in the introduction, the objective of this paper is to evaluate the effect of uncertainty of the Brexit on the exchange rate. In doing so, we extrapolate the future value of the exchange rate and the associated realized volatility based on the most accurate models and compare them with actual data. In order to produce levels of the exchange rate we follow a "quasi" recursive scheme, adding the ex-ante forecasted return to the actual level price of the previous month. In Figure 4 we depict the USD/GBP exchange rate for June 2016 based on the SVR (Polynomial) model.

\footnotetext{
${ }^{3}$ The results of the $t$-tests are available upon request from the authors.
} 


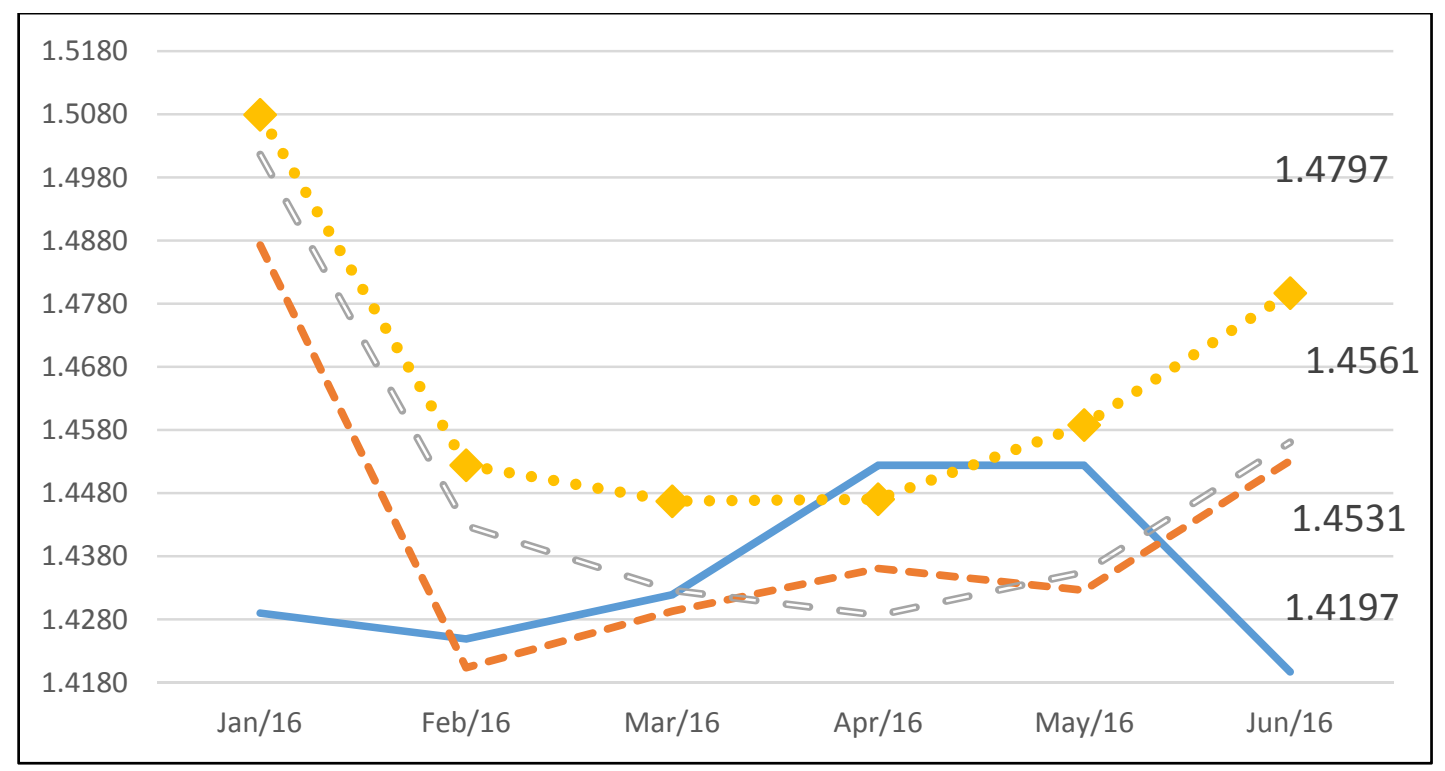

Figure 4: USD/GBP exchange rate forecasts.

Note: The straight (blue) line denotes the actual USD/GBP exchange rate, the dashed hollow line the AR forecast and the solid dotted (orange) line the Brexit EPU forecasts. The dotted (yellow) line with the star marker denotes relative Brexit forecasts. In each case we built ex ante forecasts based on the most accurate model in terms of methodology, lags and regressors.

As we observe from figure 4, both the AR and the Brexit EPU overestimate the value of the exchange rate in June, returning to the values of April 2016 before the Brexit. In Figure 5 we depict the realized variance forecasts. As we observe, the model that includes the Brexit index forecasts more accurately than the AR model the realized volatility following the Brexit, 


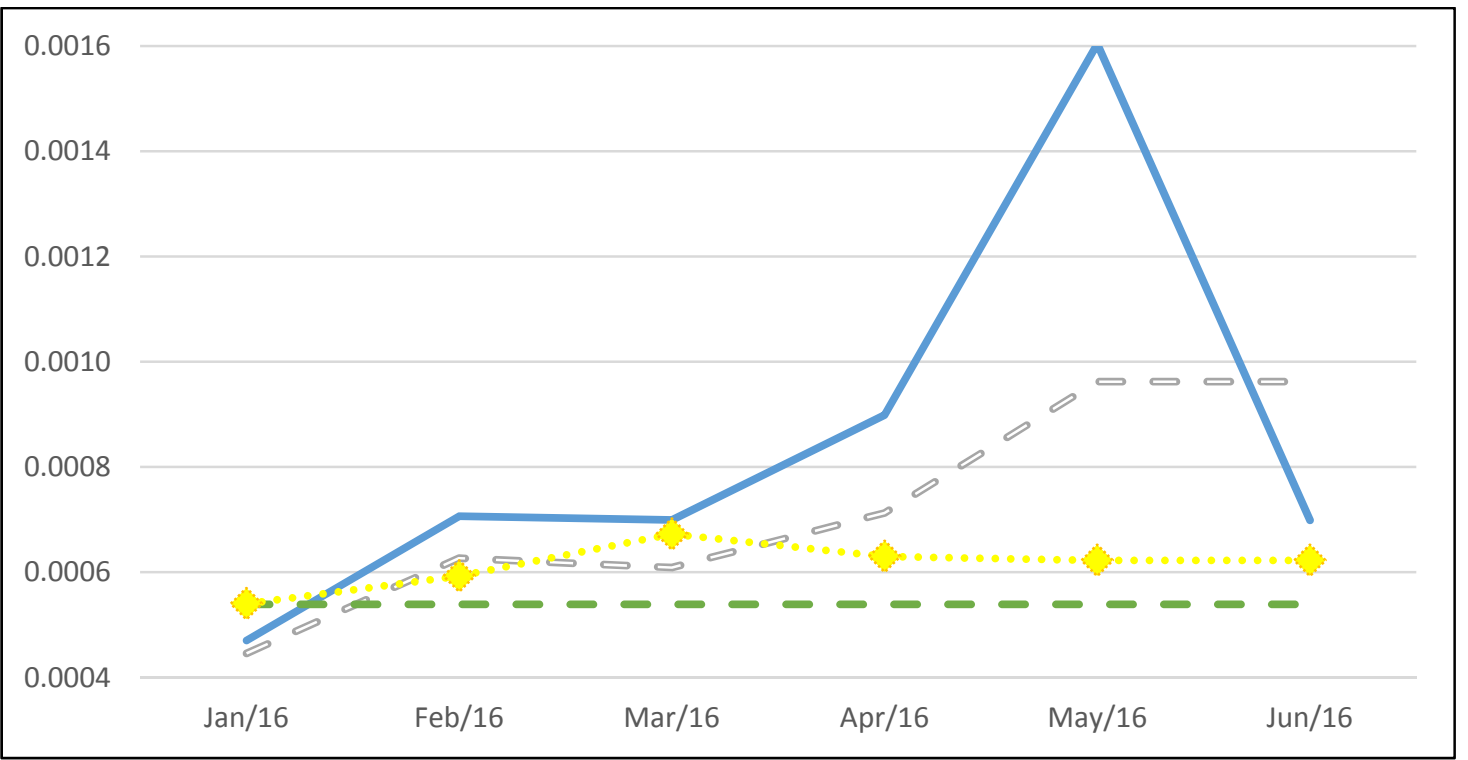

Figure 5: USD/GBP realized variance.

Note: The straight (blue) line denotes the actual USD/GBP exchange rate variance, the dashed hollow line the AR forecast and the solid dotted (orange) line the Brexit EPU forecast. The dotted (yellow) line with the star marker denotes relative Brexit forecasts. In each case we built ex ante forecasts based on the most accurate model in terms of methodology, lags and regressors.

Thus, taking in account both the exchange rate and the realized volatility of the USD/GBP exchange rate, we find that the Brexit caused an increase in the volatility of the exchange rate as traders feared of a potential currency collapse. Nevertheless, no model is able to accurately capture the exact value of the exchange rate or the magnitude of the exchange rate variance. We attribute this fact to the monthly frequency of our data, since in monthly frequency valuable information is smoothed out. Thus we repeat our analysis based on daily data.

\subsection{Daily Results}

Since the Brexit EPU index is available only until May 2016, we repeat our forecasting exercise based on the daily relative EPU computed as the differences in the logs of daily UK and US EPU indices. The usage of daily data, on the one hand reflects more closely the variability of uncertainty in the post-Brexit period, while on the other hand allows for modelling the effect of the uncertainty index on the exchange rate in the turmoil caused by the results of the referendum. Understandably, though we use overall EPUs for the UK and the US, most of the uncertainty since June 23 in these indices are likely to be caused by the Brexit.

As already stated, we use first logarithmic differences for the exchange rate, while both the UK EPU and the relative EPU index are used in levels. We again train our 
models on the period $01 / 01 / 2001$ to $31 / 12 / 2007$ and keep the period $02 / 01 / 2008-$ 08/08/2016 for pseudo out-of-sample forecasting. In contrast to the monthly frequency, the use of the UK EPU allows for observing the forecasting ability of the model in the post-Brexit period. We train our forecasting models based on the OLS and the SVR methodologies. Unfortunately, due to the high dimensionality of our sample only the SVR model with the linear kernel converged in a timely manner. ${ }^{4}$

\begin{tabular}{l|c|c|c|c|c}
\hline \hline \multicolumn{1}{c}{ Table 5: Root Mean Square Error for Out-of-Sample Forecasting of the Exchange Rate Returns } \\
\hline Regressors & $\begin{array}{c}\text { OLS } \\
\text { (RMSE } \times 100)\end{array}$ & $\begin{array}{c}\text { SVR-linear } \\
(\text { RMSE } \times 100)\end{array}$ & $\begin{array}{c}\text { SVR- } \\
\text { RBF }\end{array}$ & $\begin{array}{c}\text { SVR- } \\
\text { Sigmoid }\end{array}$ & SVR-Poly \\
\hline AR & 1.072 & 1.074 & NC & NC & NC \\
UK EPU & 1.072 & 1.073 & NC & NC & NC \\
Relative UK EPU & 1.073 & 1.074 & NC & NC & NC \\
AR-UK EPU & $1.071^{*}$ & $1.071^{*}$ & NC & NC & NC \\
AR- Relative UK EPU & 1.072 & 1.072 & NC & NC & NC \\
\hline \hline
\end{tabular}

Note: * denotes the smallest RMSE in out-of-sample forecasting. NC denotes that the model did not converge.

As we observe from Table 5, the OLS and the SVR models have equivalent forecasting ability, while the most accurate model in both cases is the model that includes lags of the exchange rate and the UK EPU (specifically 6 lags for the OLS and 5 lags for the SVR - linear model ${ }^{5}$ ). Forecasting based on the most accurate models we get the exchange rate predictions of Figure 6. Again we use a "quasi" recursive scheme to produce our forecasts for the exchange rate level, adding the exante forecasted return to the actual level price of the previous day.

As with the results of Table 5, in Figure 6 we observe that the difference between the forecasts are statistically insignificant. Both models forecast a milder depreciation immediately after the referendum, while when the exchange rate fluctuates between $1.35-1.30 \$ / £$ the forecasting error is smaller. The sharp depreciation in the aftermath of the referendum implies that this is a structural break for the exchange rate series, since the series has moved sharply from its short-term mean and continued in a lower price zone afterwards. Indeed the Quandt-Andrews Breakpoint Test (Quandt, 1960 and Andrews, 1993) gives a maximum LR F-statistic 345.56 on the $23^{\text {rd }}$ of June 2016

\footnotetext{
${ }^{4}$ All models are trained in an octacore Intel Core 2 Duo $2.10 \mathrm{GHz}$ processor with 8 GB of RAM. Only the linear SVR model converged in the desirable train time of one week.

${ }^{5}$ All detailed results for all lags are available upon request.
} 
to be a break point ${ }^{6}$, over the subsample 01 Sep $2015-08$ Aug 2016. Thus, is would be interesting to retrain the model of Figure 6 up until the $23^{\text {rd }}$ of June and get ex-ante forecasts until the end of our sample.



Figure 6: Ex-ante forecasts before the Brexit

Note: The blue line depicts the actual exchange rate, while the grey and orange lines represent models' forecasts. The lateral (red) line denotes the date of the Brexit.

In Figure 7 we report the results from the ex-ante forecasts after the Brexit. The forecasts are made using the OLS model with 6 lags of the exchange rate returns and the UK EPU index based on the "quasi" recursive transformation in levels".

\footnotetext{
${ }^{6} \mathrm{p}$-value $=0.00$ rejecting the null hypothesis of no structural break in this date

${ }^{7}$ For the sake of comparison, we also constructed the ex-ante forecasts based on the relative EPU (the difference between the UK and US EPU indices) as in the monthly frequency, but the results are quantitatively similar. Complete details are available upon request from the authors.
} 


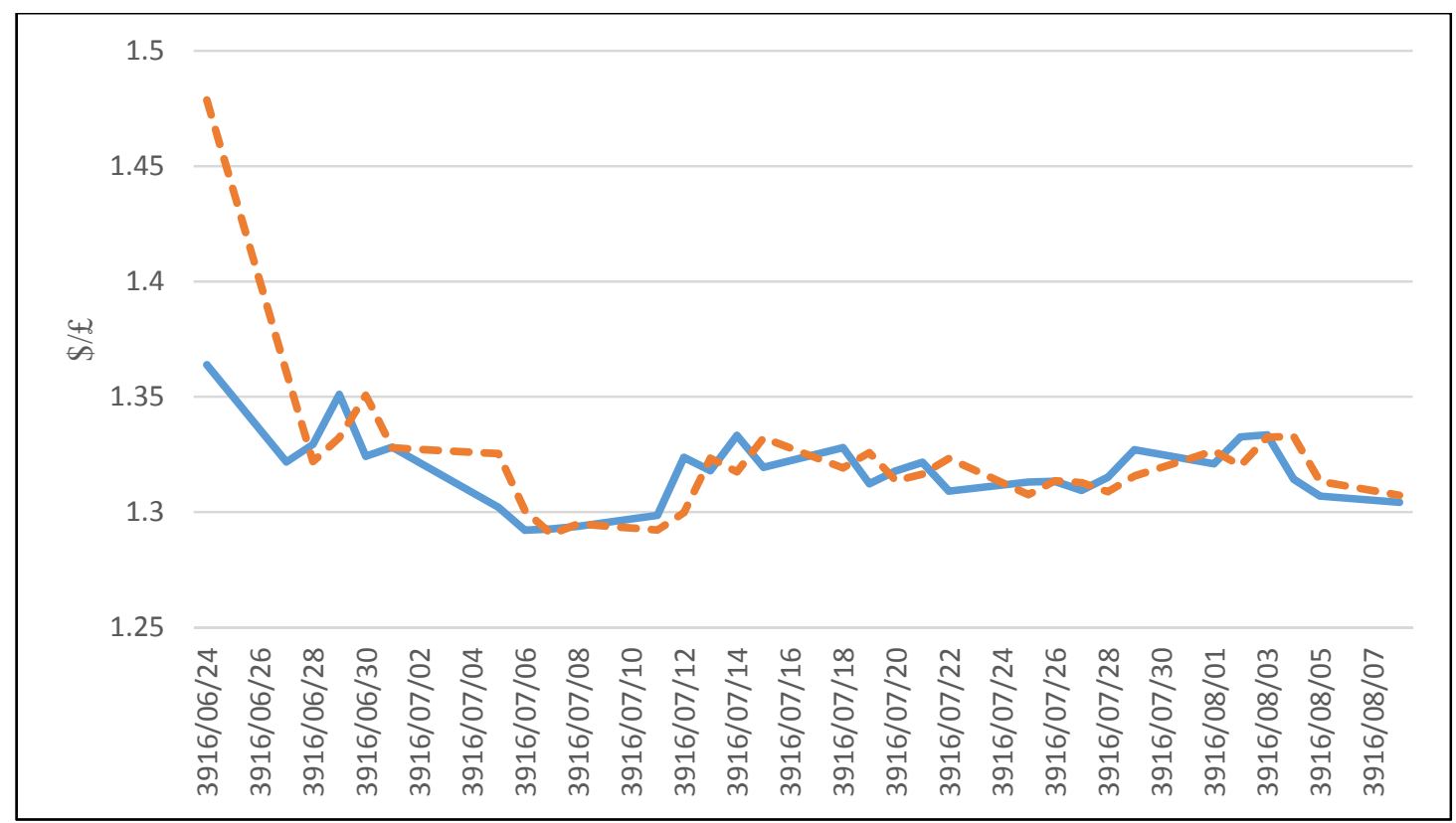

Figure 7: Post Brexit ex-ante forecasts

Note: The dashed line expresses ex-ante forecasts, while the continuous line the actual exchange rate.

As we observe, the forecasts adhere closely to the evolution of the exchange rate with two days delay. Thus the depreciation of the exchange rate is considered a structural break that can be foreseen if we use the UK EPU index. Overall, the uncertainty index is a useful tool in predicting the effect of the Brexit on the exchange rate.

\section{Conclusion}

In this paper we examine the effect of the Brexit in the significant depreciation in the USD/GBP exchange rate. The economic uncertainty caused by the decision of UK to conduct a referendum is quantified by the dedicated Economic Policy Uncertainty index that measures the ratio of newspaper articles discussing the Brexit. After training both linear and nonlinear models on daily and monthly frequencies, we select the ones that best adheres to the evolution of the exchange rate based on an out-ofsample forecasting exercise. Our empirical findings find that that the use of the uncertainty index is preferred for predicting the evolution of the exchange rate.

\section{References}

Andersen T.G. , Bollerslev T. 1998. Answering the Skeptics: Yes, Standard Volatility Models Do Provide Accurate Forecasts. International Economic Review, 39 (4), 885-905. 
Andrews D.W.K. 1993. Tests for Parameter Instability and Structural Change with Unknown Change Point. Economelrica. July, 61:4, pp. 821-56.

Baker S., Bloom N. and Davis S. 2015 "Measuring Economic Policy Uncertainty", NBER Working Paper Series, No 21633.

Balcilar, M., Gupta, R., Kyei, C., and Wohar, M.E. 2016a. Does Economic Policy Uncertainty Predict Exchange Rate Returns and Volatility? Evidence from a Nonparametric Causality-in-Quantiles Test. Open Economies Review, 27 (2), 229-250.

Chang C-C and Lin C-J, 2011, LIBSVM : a library for support vector machines. ACM Transactions on Intelligent Systems and Technology, vol. 2(27), pp. 1-27.

Dickey, D. and Fuller, W. 1981, "Likelihood Ratio Statistics for Autoregressive Time Series with a Unit Root", Econometrica, Vol. 49, 1057-1072.

Macdonald R. 2010 Exchange Rate Economics: Theory and Evidence. 1st Edition. New York: Routledge.

Phillips, P.C.B and P. Perron 1988, "Testing for a Unit Root in Time Series Regression", Biometrika, vol. 75 ,pp. 335-346.

Plakandaras V. Papadimitriou T. and Gogas P. 2015 "Forecasting monthly and daily exchange rates with machine learning methodologies", Journal of Forecasting, vol. 34 (7), pp. 560-573.

Quandt R. 1960. 'Tests of the Hypothesis that a Linear Regression Obeys Two Separate Regimes.” Journal of the American Statistical Association. 55, pp. 32430 .

Rubio G. Pomares H., Rojas I., and Herrera L.. 2011. A heuristic method for parameter selection in LS-SVM: Application to time series prediction." International Journal of Forecasting, vol. 27(3), pp. 725-739.

Vapnik, V., Boser, B. and Guyon, I. 1992. A training algorithm for optimal margin classifiers, Fifth Annual Workshop on Computational Learning Theory, Pittsburgh, ACM, pp.144-152. 